\title{
Development and implementation of incident response near-infrared models for analyzing contaminated medicines containing diethylene glycol solvent
}

\author{
Lihui Yin, Xuebo Zhang, Xiaodong Li and Shaohong Jin* \\ National Institutes for Food and Drug Control \\ No. 2 Tiantan Xili, Beijing, P. R. China \\ *jinshh@nifdc.org.cn
}

Received 26 August 2013

Accepted 1 December 2013

Published 17 June 2014

\begin{abstract}
Samples of preparations contaminated by diethylene glycol (DEG), diethylene glycol raw materials and laboratory prepared solutions were measured to get NIR spectra. Then the identification models were developed using the collected spectra and the spectra of distilled water, propylene glycol and the preparations without diethylene glycol. Besides, the quantification model was also established for determining the concentration of diethylene glycol in the preparations. Validation results show the identification and quantification models have ideal prediction performance. The emergency NIR models are rapid, easy to use and accurate, and can be implemented for identifying diethylene glycol raw material, screening the preparations contaminated by diethylene glycol in the markets and analyzing the concentrations of DEG.
\end{abstract}

Keywords: Diethylene glycol; near-infrared transmittance-reflectance spectroscopy; identification; quantification.

\section{Introduction}

Counterfeit drugs are a substantial and growing problem, both in the developing and developed countries. ${ }^{1,2}$ In order to mobilize awareness and action in the fight against fake drugs, World Health Organization (WHO) created the first global partnership known as the International Medicinal Products Anti-Counterfeiting Taskforce (IMPACT) in February 2006. ${ }^{3}$ In China, 400 mobiles labs have been put into use by State Food and Drug Administration of China since 2005 in an effort to crackdown the counterfeit and substandard drug, which have highly improved the efficiency and scale of drug testing in Chinese markets. ${ }^{4,5}$ Mobile labs have gained praises from WHO and experts from the countries in Europe, America, Africa and Southeast Asia, and also enhanced the communication and cooperation in the field of rapid drug testing between China and other countries.

In the cases of counterfeit and substandard medicines, drug safety incidents require highest attentions. Over the years, the toxic solvent diethylene

This is an Open Access article published by World Scientific Publishing Company. It is distributed under the terms of the Creative Commons Attribution 3.0 (CC-BY) License. Further distribution of this work is permitted, provided the original work is properly cited. 
glycol (DEG) has been loaded into all varieties of medicine - cough syrup, fever medication and injectable drugs. The irresponsible manufacturers or counterfeit drug groups get profit by substituting the sweet-tasting solvent for a safe, more expensive syrup, usually glycerin. In late 1995 and early 1996, at least 80 children died in Haiti due to DEGcontaminated glycerin in acetaminophen syrup. Between 1990 and 1998, similar incidents of DEG poisoning reportedly occurred in Argentina, Bangladesh, India, and Nigeria and resulted in hundreds of deaths. ${ }^{6}$ In the most recent incident, the paracetamol syrup for children adulterated with DEG caused 24 deaths in Bangladesh in 2009. ${ }^{7}$ Reasons for the drug safety incidents mainly include: (1) counterfeit drugs that were deliberately produced by criminals with ever increasing sophistications in equipments and methods; (2) unqualified drugs that was produced by the legitimate manufactures in which the manufacturing process was out of control accidentally, but failed to be detected by quality Control procedures and then subsequently released to the market; or (3) drugs that no longer meet the quality requirements are due to poor storage and inadequate transportation conditions.

In the emergency responses to drug safety incidents, near-infrared (NIR) spectroscopy as a rapid, easy to use and contaminated-free technology can be utilized for quickly screening the suspicious medicines. ${ }^{8}$ Specific NIR models for certain medicines can be developed and implemented in short time and equipped in the mobile labs to detect counterfeit or substandard medicines. The emergency response NIR technique using identification and quantification models have the characteristics of fast development, rapid $100 \%$ batch-to-batch testing, and reliable screening on specific targets.

DEG incident also occurred in China. In 2006, a pharmaceutical manufacturer made a faulty liquid injections that killed 13 people in southern China city of Guangzhou. The pharmaceutical manufacturer (Qiqihar No. 2 Pharmaceutical Co.) used the toxic DEG instead of the relatively benign but more expensive 1,2-dihydroxypropane in the manufacturing process of armillarisin A, an antibiotic for treating gall bladder and gastric conditions. Under this circumstance, emergency NIR models for DEG raw material and the preparations containing DEG were developed for rapidly screening the suspicious drugs in the market. Present paper introduces the experimental approach and the validation results, which may be valuable for the development of other emergency NIR models in future.

\section{Materials and Methods}

\subsection{Samples}

Samples of distilled water, 11 batches of DEG (Eagle Chemical Co., Ltd., Changzhou China), five batches of 1,2-dihydroxypropane (Shenyang Chemical Co., Walter) and three batches of 1,3-dihydroxypropane (Shenyang Chemical Co., Walter) were used. A total of 17 batches of predetermined contaminated samples containing DEG and 100 batches of samples without DEG were used from the markets. A total of 20 laboratory prepared DEG water solutions with distilled water under various volume concentrations from $5-100 \%$ with increment of $5 \%$ were used.

\subsection{Instruments and data acquisition}

Spectra acquisition was performed on Matrix-F Fourier-Transformed NIR spectrometer (Bruker Optics Inc., Germany). Fiber optic probe with liquid measurement accessory were used to collect transmittance-reflectance spectra with InGaAs (Indium gallium arsenide) detector. Spectral range was $12,000-4000 \mathrm{~cm}^{-1}$, and the resolution was $4 \mathrm{~cm}^{-1}$. Each sample was measured three times producing three original spectra, and each original spectrum corresponds to the average of 32 scans. The environment temperature was $28^{\circ} \mathrm{C}$. Original spectra were used for identification and quantification models development.

The concentrations of DEG were analyzed by gas chromatography method on Agilent 6890N Network GC System (USA, United States). Capillary column is OV-1 $15 \mathrm{~m}^{*} 0.2 \mathrm{~mm}^{*} 0.25 \mu \mathrm{m}$, column temperature is increased from initial $80^{\circ} \mathrm{C}$ to $260^{\circ} \mathrm{C}$ by the rate of $10^{\circ} \mathrm{C}$ per minute. Injection temperature was $250^{\circ} \mathrm{C}$, pre-column pressure was $55 \mathrm{KPa}$, temperature of connection wires were $280^{\circ} \mathrm{C}$ and split ratio was $1 / 30$.

\subsection{Model development}

Bruker OPUS 5.0 software (Bruker Optics, Germany) was used for developing NIR models. Identification models were developed by factorization 
algorithm and Euclidean distances, and quantification model was developed using PLS1 algorithm (PLS regression for one $y$-variable). ${ }^{9,10}$ The unit of content concentration is $\mathrm{mg} \cdot \mathrm{ml}^{-1}$. Validation methods of the calibration model include leave-oneout cross-validation (LOOCV) and test set validation (TSV), yielding root mean square errors called RMSECV and RMSEP, respectively, to assess the quality of models.

In the quantification model, the number of PLS factors is determined by one-sided F-test on PRESS [PRediction Error Sum of Squares, Eq. (1)] in LOOCV at $\alpha=0.05$ to identify the model with fewest factors whose PRESS is not significantly different from the lowest one within the first 20 factors. $R^{2}$ is coefficient of determination, giving the percentage of variance present in the true component values, which is reproduced in the prediction [Eq. (2)].

$$
\begin{gathered}
\operatorname{PRESS}=\sum_{i=1}^{M}\left(\text { Differ }_{i}\right)^{2} \\
R^{2}=\left(1-\frac{\sum_{i=1}^{M}\left(\text { Differ }_{i}\right)^{2}}{\sum_{i=1}^{M}\left(Y_{i}-Y_{m}\right)^{2}}\right) \times 100,
\end{gathered}
$$

where $M$ is the number of samples for model validation, $Y_{m}$ is the mean of true concentration values, Differ $_{i}$ is the difference between true value and prediction value [Eq. (3)]:

$$
\operatorname{Differ}_{i}=Y_{i}^{\text {true }}-Y_{i}^{\text {pred }}
$$

The calculations of RMSECV and RMSEP are shown in Eqs. (4) and (5), respectively.

$$
\begin{gathered}
\text { RMSECV }=\sqrt{\frac{1}{M_{l}} \cdot \sum_{i=1}^{M_{l}}\left(\text { Differ }_{i}\right)^{2}}, \\
\text { RMSEP }=\sqrt{\frac{1}{M_{t}} \cdot \sum_{i=1}^{M_{t}}\left(\text { Differ }_{i}\right)^{2}}
\end{gathered}
$$

where $M_{l}$ and $M_{t}$ are the numbers of samples in LOOCV and TSV, respectively.

\section{Results and Discussion}

\subsection{Identification model for DEG raw material}

This model consisted of four groups, including DEG (33 spectra), 1,2-dihydroxypropane (15 spectra), 1,3-dihydroxypropane (9 spectra) and distilled water (6 spectra). Spectral ranges for model construction is shown in Fig. 1, i.e., $5500-6400 \mathrm{~cm}^{-1}$ and $4200-4700 \mathrm{~cm}^{-1}$, corresponding to the first overtone and first combination absorption ranges of $\mathrm{CH}$ group, respectively. Spectral data were pretreated by Savitzky-Golay ${ }^{11}$ first derivative and standard normal variate (SNV). ${ }^{12,13}$

After factorization, the first, second and third factors were used for constructing the identification model. Euclidean distance threshold for each group

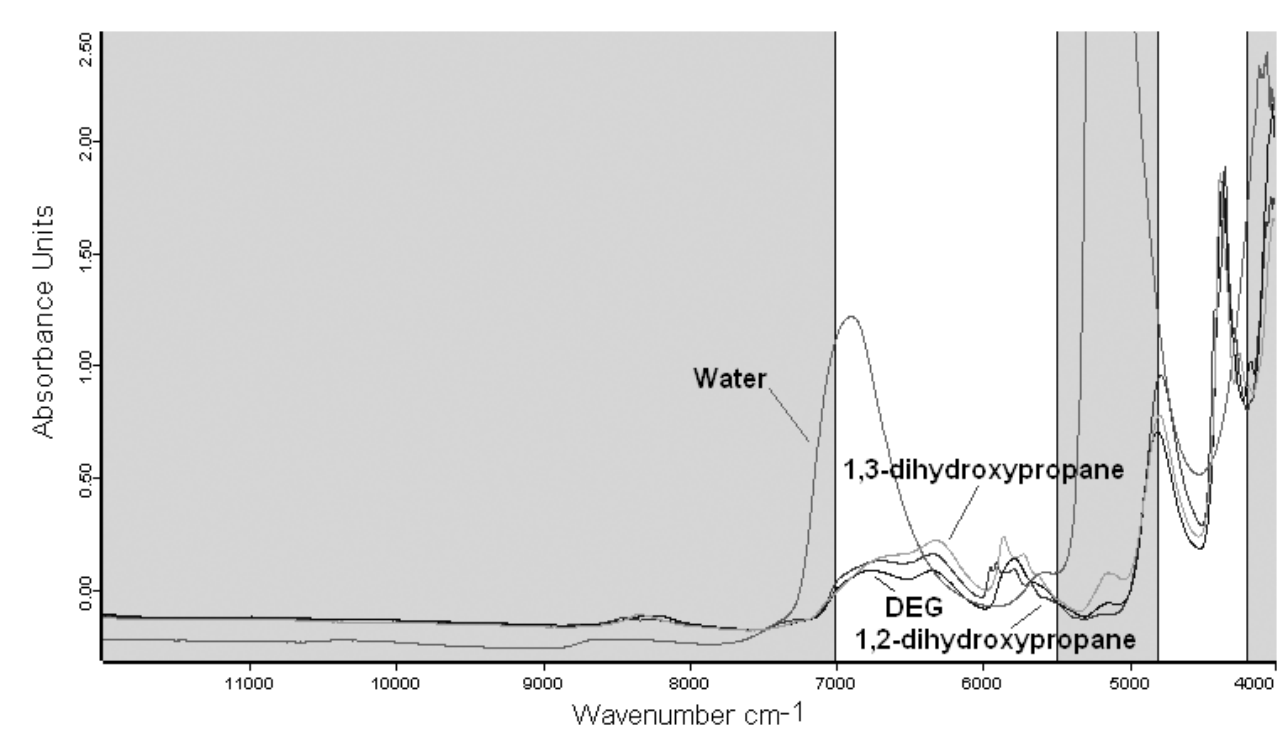

Fig. 1. Spectral ranges in the identification method for DEG raw material (white area). 


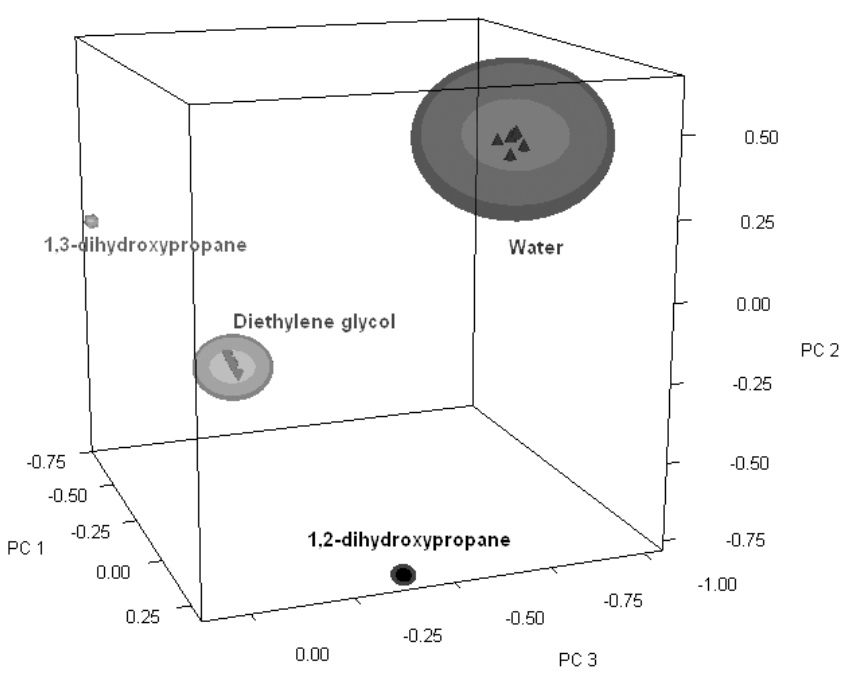

Fig. 2. Principal component score plot of the NIR spectra of each group in the identification method for DEG raw material.

was determined by setting confidence interval as 99.99\%. The principal component score plot of the spectra in each group has shown a well separation suggesting the model is able to distinguish different samples (Fig. 2).

Identification of the DEG water solutions under different volume concentrations using this model shows that samples over $85 \%$ are recognized as "DEG". The Euclidean distances of the DEG water solutions from $100-50 \%$ (with decrement of $5 \%$ ) to average spectrum of "DEG" group (threshold is 0.114) are shown in Table 1.

Besides, the Euclidean distances of the 1,2-dihydroxypropane water solutions from 100-5\% (with decrement of $5 \%$ ) to the "1,2-dihydroxypropane" group (threshold is 0.03 ) in the identification model are also calculated and shown in Fig 3. Only the solutions of concentrations not lower than $90 \%$ are identified as 1,2dihydroxypropane.

The validation results show that the model has good performance to distinguish different raw materials and recognize the raw materials with slightly low concentrations.

\subsection{Identification model for the preparations containing DEG}

In order to identify DEG in commercial medicines, additional identity model was developed. This model contains two groups, preparations containing DEG and preparations without DEG. The group "preparations containing DEG" includes eight samples (24 spectra) of the laboratory prepared DEG water solutions of volume concentrations from $5 \%$ to $40 \%$ with increment of $5 \%$ and 7 batches $(21$ spectra) of the preparations containing DEG from the markets (one batch of betamethasone sodium phosphate injection, one batch of armillarisni A injection, one batch of nefopam hydrochloride injection, two batches of puerarin injection and two batches of pediatric paracetamol enema). The group "preparations without DEG" includes two batches of puerarin injection, two batches of pediatric paracetamol enema and two batches of betamethasone sodium phosphate injection (total of 18 spectra) which are not contaminated by DEG. Spectral ranges for model construction are 6220 $5610 \mathrm{~cm}^{-1}$ and $4290-4620 \mathrm{~cm}^{-1}$, as shown in Fig. 4 and spectral pretreatment method is SavitzkyGolay second derivative and SNV. After model optimization, the first and second factors were used for model construction.

A total of 104 batches of preparations from the market were identified by this model, and the results are shown in Table 2.

As shown in Table 2, five batches of preparations without DEG are misidentified as the preparations containing DEG, and preparations without containing DEG is identified falsely. In fact, a proper level of false positive rate is acceptable, but false negative rate should be near zero to prevent the counterfeit and substandard medicines being recognized as authentic ones.

Table 1. Spectral distances of DEG solutions under different concentrations to the group "DEG" in the identification model.

\begin{tabular}{|c|c|c|c|c|c|c|c|c|c|c|c|}
\hline $\begin{array}{l}\text { Volume concentration of } \\
\text { DEG water solutions }\end{array}$ & $100 \%$ & $95 \%$ & $90 \%$ & $85 \%$ & $80 \%$ & $75 \%$ & $70 \%$ & $65 \%$ & $60 \%$ & $55 \%$ & $50 \%$ \\
\hline $\begin{array}{l}\text { Spectral } \\
\text { distances }\end{array}$ & 0.021 & 0.023 & 0.084 & 0.140 & 0.184 & 0.250 & 0.300 & 0.345 & 0.414 & 0.438 & 0.478 \\
\hline
\end{tabular}




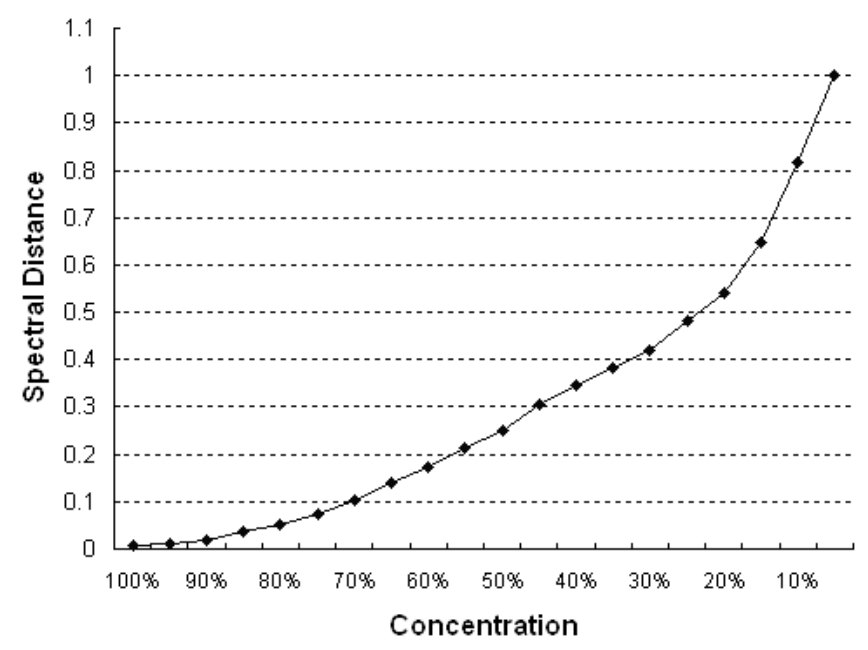

Fig. 3. Plot of spectral distances of 1,2-dihydroxypropane solutions under different concentrations to the group " 1,2 dihydroxypropane" in the identification model.

\subsection{Quantification model for DEG in the preparations}

Li et al. had developed PLS quantitative model for the detection of DEG contamination in propylene glycol-water mixtures. ${ }^{14}$ In the present work, quantitative model for DEG in the preparations was established.

A total of 20 laboratory prepared DEG water solutions and six batches of preparations containing DEG from the market are used to develop the quantification model for DEG in the preparations. The concentrations of DEG in these 26 samples are shown in Table 3.

As shown in Fig. 5, several spectral ranges display the changes of absorbance under different concentrations, and $7502.1-5446.2 \mathrm{~cm}^{-1}$ and $4601.5-4246.7 \mathrm{~cm}^{-1}$ were chosen to develop the quantification model after model optimization. The spectral pretreatment methods are Savitzky-Golay first derivative (17 smoothing points) and multiplicative scatter correction (MSC).

A total of 26 calibration samples were used for developing the quantification model, and another 11 preparations from the markets were used as independent test samples. The cross-validation and TSV results are shown in Fig. 6. The number of PLS factors is $8, R^{2}$ of cross-validation and TSV are 99.66 and 96.68, RMSECV and RMSEP are 18.7 and 44.2 , respectively.

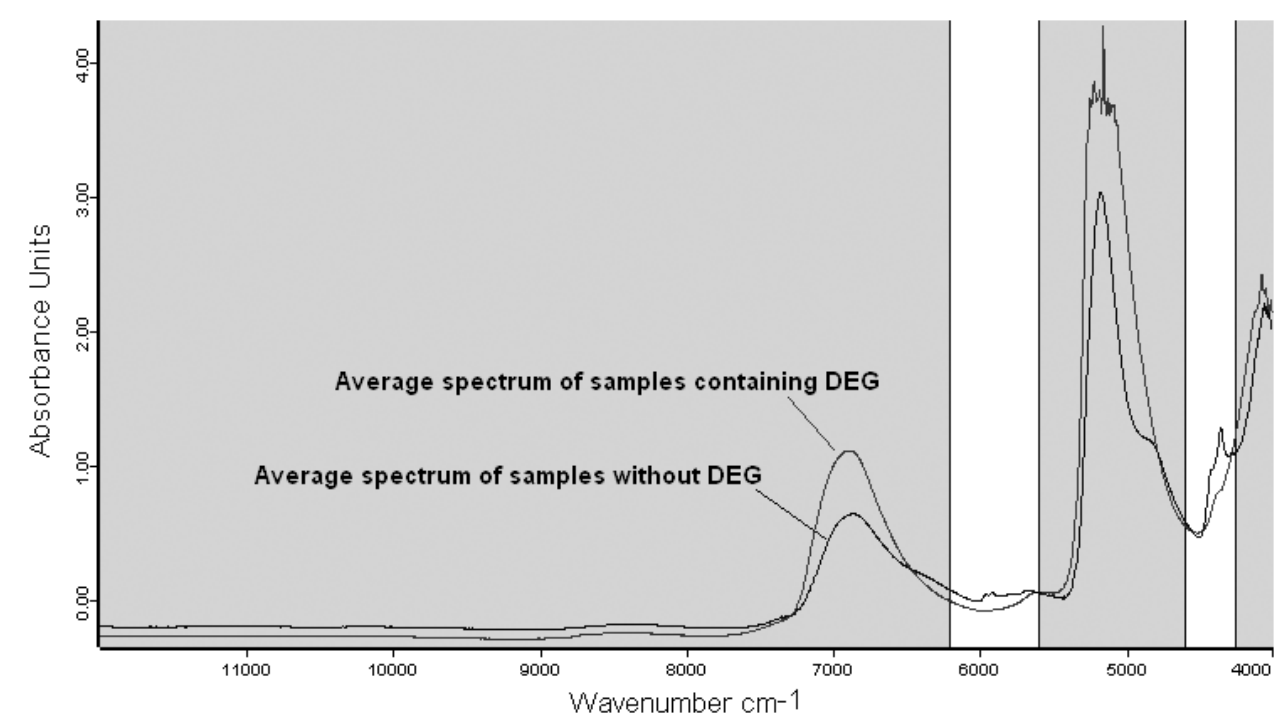

Fig. 4. Spectral ranges of the identification method for the preparations containing DEG (white area).

Table 2. Validation results of the identification method for the preparations containing DEG.

\begin{tabular}{lcccc}
\hline Preparations & $\begin{array}{c}\text { No. of samples } \\
\text { validated }\end{array}$ & $\begin{array}{c}\text { No. of samples } \\
\text { wrongly identified }\end{array}$ & $\begin{array}{c}\text { Percentage of correct } \\
\text { identification(\%) }\end{array}$ & $\begin{array}{c}\text { Percentage of incorrect } \\
\text { identification(\%) }\end{array}$ \\
\hline Preparations without DEG & 94 & 5 & 94.7 & 5.3 \\
Preparations containing DEG & 10 & 0 & 100.0 & 0.0 \\
\hline
\end{tabular}


L. Yin et al.

Table 3. DEG concentration of 26 samples for developing calibration model.

\begin{tabular}{|c|c|}
\hline Calibration samples & Content concentration $\mathrm{mg} \cdot \mathrm{ml}^{-1}$ \\
\hline $5 \%$ DEG water solution & 57.5 \\
\hline $10 \%$ DEG water solution & 115.0 \\
\hline $15 \%$ DEG water solution & 172.5 \\
\hline $20 \%$ DEG water solution & 230.0 \\
\hline $25 \%$ DEG water solution & 287.5 \\
\hline $30 \%$ DEG water solution & 345.0 \\
\hline $35 \%$ DEG water solution & 402.5 \\
\hline $40 \%$ DEG water solution & 460.0 \\
\hline $45 \%$ DEG water solution & 517.5 \\
\hline $50 \%$ DEG water solution & 575.0 \\
\hline $55 \%$ DEG water solution & 632.5 \\
\hline $60 \%$ DEG water solution & 690.0 \\
\hline $65 \%$ DEG water solution & 747.5 \\
\hline $70 \%$ DEG water solution & 805.0 \\
\hline $75 \%$ DEG water solution & 862.5 \\
\hline $80 \%$ DEG water solution & 920.0 \\
\hline $85 \%$ DEG water solution & 977.5 \\
\hline $90 \%$ DEG water solution & 1035.0 \\
\hline $95 \%$ DEG water solution & 1092.5 \\
\hline $100 \%$ DEG water solution & 1150.0 \\
\hline Contaminated betamethasone sodium phosphate injection (batch no. 04122603) & 361.0 \\
\hline Contaminated armillarisni A injection (batch no. 06030501) & 310.0 \\
\hline Contaminated nefopam hydrochloride injection (batch no. 05071901) & 61.0 \\
\hline Contaminated pediatric acetaminophen enema (batch no. 05090201) & 716.0 \\
\hline Contaminated armillarisni A injection (batch no. 05102801) & 377.0 \\
\hline Contaminated puerarin injection (batch no. 05062403) & 424.0 \\
\hline
\end{tabular}

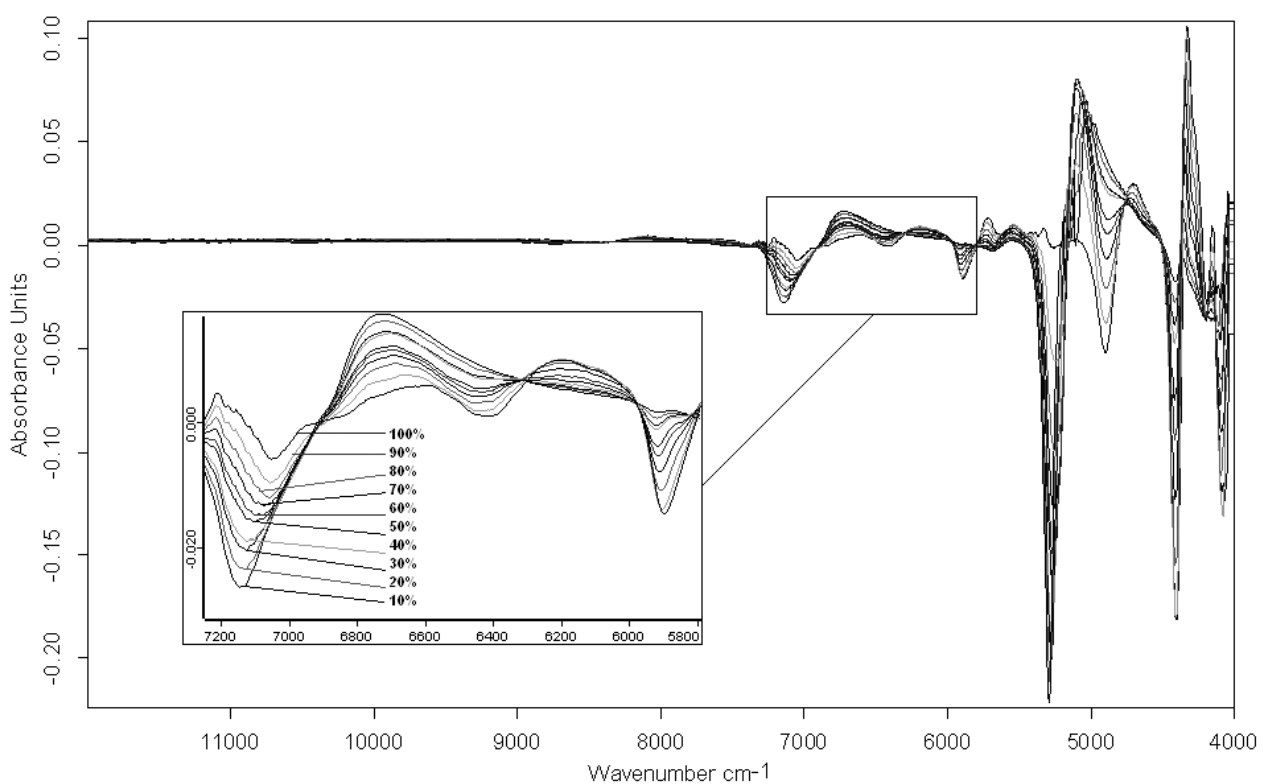

Fig. 5. Spectra of laboratory prepared samples under different volume concentrations of DEG (preprocessed by Savitzky-Golay first derivative and vector normalization). 

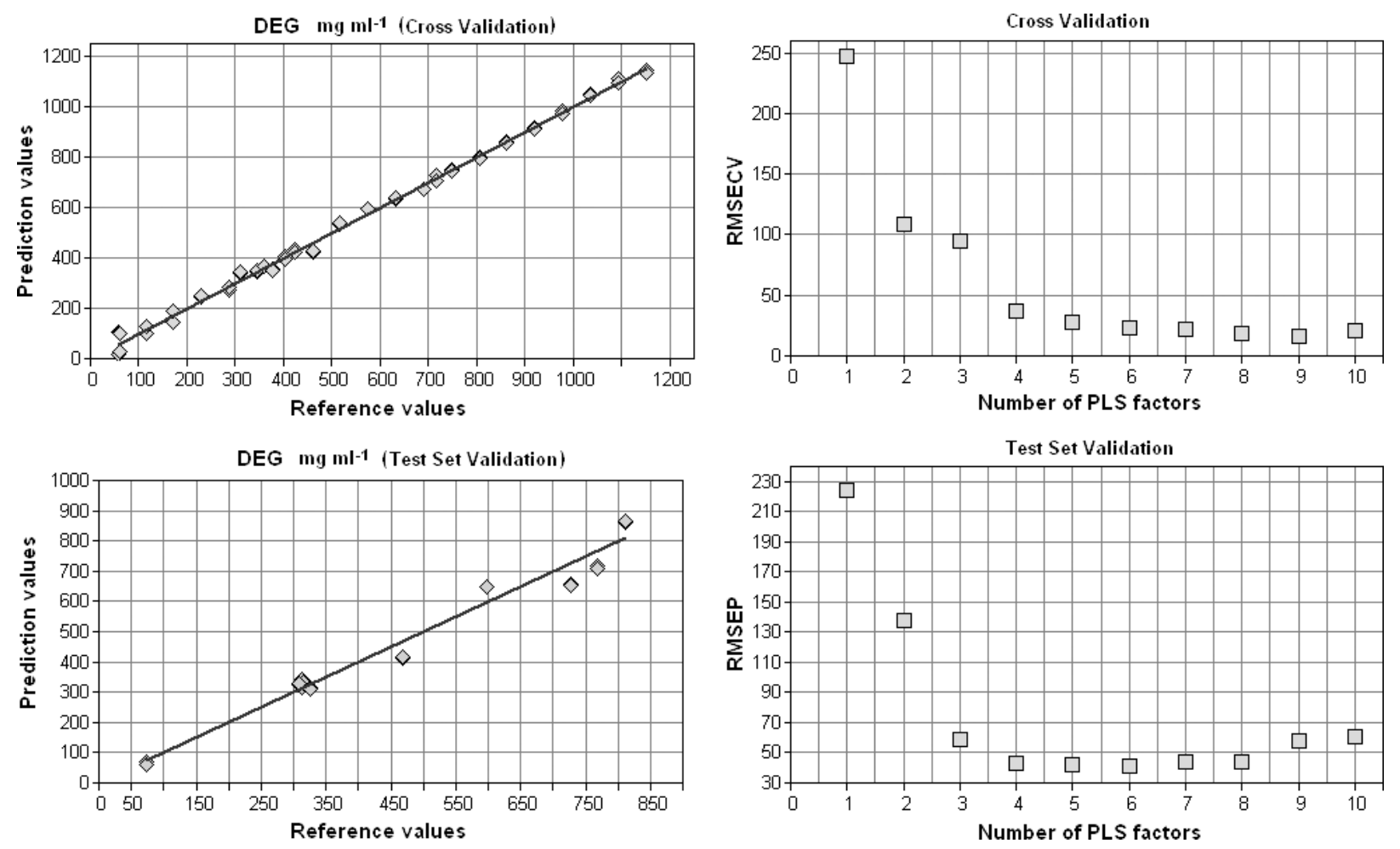

Fig. 6. Validation results of the calibration model for the preparations containing DEG.

Table 4. Prediction results of real commercial samples by the calibration model for the preparations containing DEG.

\begin{tabular}{|c|c|c|c|c|}
\hline Preparations & $\begin{array}{l}\text { Reference value } \\
\mathrm{mg} \cdot \mathrm{ml}^{-1}\end{array}$ & $\begin{array}{l}\text { NIR prediction } \\
\text { value } \mathrm{mg} \cdot \mathrm{ml}^{-1}\end{array}$ & $\begin{array}{l}\text { Deviation } \\
\mathrm{mg} \cdot \mathrm{ml}^{-1}\end{array}$ & $\begin{array}{c}\text { Relative } \\
\text { deviation\% }\end{array}$ \\
\hline $\begin{array}{l}\text { Contaminated armillarisni A injection } \\
\text { (batch no. 06040903) }\end{array}$ & 314 & 327.5 & -13.4 & 4.3 \\
\hline $\begin{array}{l}\text { Contaminated betamethasone sodium phosphate } \\
\text { injection (batch no. 04122803) }\end{array}$ & 316 & 330.2 & -14.2 & 4.5 \\
\hline $\begin{array}{l}\text { Contaminated puerarin injection } \\
\quad \text { (batch no. } 05063001 \text { ) }\end{array}$ & 469 & 416.2 & 52.9 & 11.3 \\
\hline $\begin{array}{l}\text { Contaminated puerarin injection } \\
\quad \text { (batch no. 05090703) }\end{array}$ & 597 & 650.2 & -53.2 & 8.9 \\
\hline $\begin{array}{l}\text { Contaminated puerarin injection } \\
\quad \text { (batch no. 05120103) }\end{array}$ & 308 & 327.0 & -19.0 & 6.2 \\
\hline $\begin{array}{l}\text { Contaminated armillarisni A injection } \\
\text { (batch no. 06022703) }\end{array}$ & 325 & 312.9 & 12.1 & 3.7 \\
\hline $\begin{array}{l}\text { Contaminated pediatric acetaminophen enema } \\
\quad \text { (batch no. 05090301) }\end{array}$ & 769 & 712.1 & 57.0 & 7.4 \\
\hline $\begin{array}{l}\text { Contaminated pediatric acetaminophen enema } \\
\text { (batch no. 05121601) }\end{array}$ & 728 & 653.9 & 74.2 & 10.2 \\
\hline $\begin{array}{l}\text { Contaminated nefopam hydrochloride injection } \\
\text { (batch no. 06031501) }\end{array}$ & 73 & 63.4 & 9.6 & 13.1 \\
\hline $\begin{array}{l}\text { Contaminated pediatric acetaminophen enema } \\
\text { (batch no. 05110101) }\end{array}$ & 812 & 867.4 & -55.4 & 6.8 \\
\hline $\begin{array}{l}\text { Contaminated pediatric acetaminophen enema } \\
\text { (batch no. 2-05110101) }\end{array}$ & 812 & 865.3 & -53.3 & 6.6 \\
\hline
\end{tabular}


In order to test the suitability and predictability of the quantification model, the model was used to predict 11 real commercial samples collected from Qiqihar No. 2 Pharmaceutical Co. The results were shown in Table 4.

\section{Conclusion}

The identification and quantification models were developed in just one day, and provided good prediction performance of DEG samples. Therefore, this technique could be served as a rapid testing method for real field implementation. When adapting this rapid NIR method in a mobile lab in Guangzhou province, 69 different batches of four kinds of injections from Qiqihar No. 2 Pharmaceutical Co. had been found containing DEG, and the identification results had been confirmed by GC method. Another benefit of the application of fast and $100 \%$ batch-to-batch testing NIR method on Guangzhou mobile lab is to realize that some preparations did contain or free of any DEG even if they were from same production batch. Under this nonuniform DEG distribution in one poorly qualified manufacturer, the traditional sampling protocol followed by routine laboratory test may not be able to prevent releasing of contaminated medicines.

Laboratory prepared samples were added to the preparations from the markets to develop the above models. By this approach, practical NIR models can be established with limited number of samples and within a short period of time. This concept, by applying quick incident response NIR technique, is really critical for protecting the patients by fast screening of counterfeit and substandard medicines.

Present study results show that NIR spectroscopic technology can be used to develop emergency models which is low cost, quick to develop and pollution tree to achieve rapid screening of the involved medicines in the drug safety incidents. Such emergency models are useful, and will be of great help to emergency reactionand protect the public health in the future.

\section{References}

1. Y. Juillet, A. P. Vlasto, "Counterfeiting of medicinal drugs: Issues and threats," Fund. Clin. Pharmacol. 19(6), 621-624 (2005).
2. World Health Organization (WHO), "Combating counterfeit drugs: A concept paper for effective international cooperation," Concept paper, WHO, Rome, 27 January 2006, Available at www.who.int/ medicines/counterfeit _conference/en/index.html.

3. International Medical Products Anti-Counterfeiting Taskforce - IMPACT, Available at http://www. who.int/impact/en/.

4. Y. C. Feng, C. Q. Hu, "The construction and feasibility study of near infrared system for fake and counterfeit drug identification," Chin. Pharm. Aff. 18(4), 250-252 (2004).

5. C. Q. Hu, W. B. Zou, W. S. HU, X. K. Ma, M. Z. Yang, S. L. Zhou, J. F. Sheng, Y. Li, S. H. Cheng, J. Xue, "Establishment of a fast chemical identification system for screening of counterfeit drugs of macrolide antibiotics," J. Pharm. Biomed. Anal. 40, 68-74 (2006).

6. FDA Advises Manufacturers to Test Glycerin for Possible Contamination, Available at http://www. fda.gov/NewsEvents/Newsroom/PressAnnouncements/2007/ucm108909.htm.

7. Bangladesh medicine 'was toxic', Available at http://news.bbc.co.uk/2/hi/south_asia/8172878. stm.

8. G. Reich, "Near-infrared spectroscopy and imaging: Basic principles and pharmaceutical applications," Adv. Drug Deliver. Rev. 57(8), 1109-1143 (2005).

9. R. G. Brereton, "Introduction to multivariate calibration in analyticalchemistry," Analyst. 125, 2125-2154 (2000).

10. D. A. Burns, E. W. Ciurczak, Handbook of NearInfrared Analysis, 3rd Edition, CRC Press, Boca Raton (2008).

11. A. Savitzky, M. J. Golay, "Smoothing and differentiation of data by simplified least squares procedures," Anal. Chem. 36, 1627-1639 (1964).

12. R. J. Barnes, M. S. Dhanoa, S. J. Lister, "Standard Normal Variate Transformation and De-trending of Near-Infrared Diffuse Reflectance Spectra," Appl. Spectrosc. 43(5), 772-777 (1989).

13. A. Garrido-Varo, R. Carrette, V. Fernandez-Cabanas, "Use of difference near infrared reflectance spectra to extract relevant information from the spectra of agro-food products," J. Near Infrared Spectrosc. 6, 89-95 (1998).

14. X. Li, S. Arzhantsev, J. F. Kauffman, J. A. Spencer, "Detection of diethylene glycol adulteration in propylene glycol - Method validation through a multiinstrument collaborative study," J. Pharm. Biomed. Anal. 54(5), 1001-1006 (2011). 